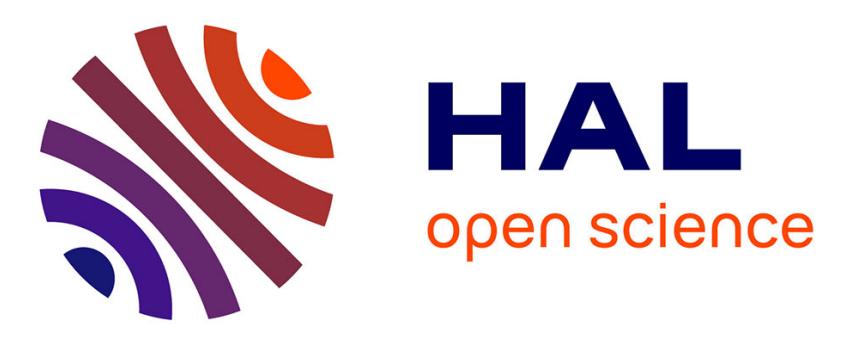

\title{
Influence of the edge rounding process on the behaviour of blanked parts: numerical predictions with experimental correlation
}

Mohamed Achouri, Eric Gildemyn, Guénaël Germain, Philippe Dal Santo, Alain Potiron

\section{To cite this version:}

Mohamed Achouri, Eric Gildemyn, Guénaël Germain, Philippe Dal Santo, Alain Potiron. Influence of the edge rounding process on the behaviour of blanked parts: numerical predictions with experimental correlation. International Journal of Advanced Manufacturing Technology, 2014, 71 (5-8), pp.10191032. 10.1007/s00170-013-5522-8 . hal-01063609

\section{HAL Id: hal-01063609 \\ https://hal.science/hal-01063609}

Submitted on 5 Sep 2017

HAL is a multi-disciplinary open access archive for the deposit and dissemination of scientific research documents, whether they are published or not. The documents may come from teaching and research institutions in France or abroad, or from public or private research centers.
L'archive ouverte pluridisciplinaire HAL, est destinée au dépôt et à la diffusion de documents scientifiques de niveau recherche, publiés ou non, émanant des établissements d'enseignement et de recherche français ou étrangers, des laboratoires publics ou privés. 


\title{
Influence of the edge rounding process on the behaviour of blanked parts: numerical predictions with experimental correlation
}

\author{
Mohamed Achouri • Eric Gildemyn • Guenael Germain • \\ Philippe Dal Santo • Alain Potiron
}

\begin{abstract}
Blanking of sheet metal is an important forming process in the automotive industry for the manufacture of mechanical components. The final component shape, obtained at the end of bending or deep-drawing processes, often has sharp edges due to the blanking operation. Concerning passenger safety components, like seat belt anchors, rounding of the edges by punching is necessary to avoid cutting the belt material. In addition to removing the sharp edges, the punching results in work hardening of the material in the rounded zones which results in an increase in the local resistance of the material. In this study, a high-strength low-alloy steel (HSLA S500MC) has been tested with the aim of quantifying the blanking and edge rounding operations. The mechanical behaviour of test specimens is investigated by means of tensile tests and the material is characterised in terms of Vickers micro-hardness. Numerical simulations of the edge rounding process are developed using previously identified material behaviour laws. The residual stress fields are characterised and compared to experimental results. This is done so that numerical simulation can be done in the future to prediction the in-service behaviour of the component. Specimens with rounded edges are compared to specimens that were not submitted to the rounding operation. It is shown that Edge Rounding by Punching improves the component resistance, therefore justifying the use of this process in the manufacture of automotive safety components.
\end{abstract}

Keywords Edge rounding by punching $\cdot$ Vickers micro-hardness $\cdot$ Residual stresses $\cdot$ Numerical simulation . High-strength low-alloy steel

\section{Introduction}

In recent decades, the automotive industry has given great importance to passenger safety devices like security belts and airbags. The mechanical components associated with automotive security are typically manufactured by successive blanking and bending operations. At the end of the manufacturing process, the component must conform to predefined standards concerning their mechanical resistance. The experimental verification of the components' mechanical behaviour involves costly testing equipment and is very time consuming. Due to increasing computational performance of computers, many physical experiments can be avoided through the use of numerical simulation $[1,2]$. The accuracy of the predicted behaviour of the virtual component depends strongly on the constitutive model used to simulate the complete manufacturing sequence. Due to the complexity of the industrial process, which is summarised in Fig. 1, the various operations of the complete forming process (i.e. blanking, Edge Rounding by Punching, E.R.P. and bending) are typically studied separately.

The sheet metal blanking operation has been investigated by several authors [3, 4] and continues to be studied [5] in view of predicting geometrical and mechanical aspects of the sheared faces of the component [6]. Stress and material damage distributions have been characterised during the blanking process and at the end of the operation by Hambli and Potiron [7]. These authors assume that fracture occurs when the material damage reaches a critical value. In terms of electronic 
Fig. 1 a Overview of the sequential operations used to manufacture the component; b a seat belt anchor
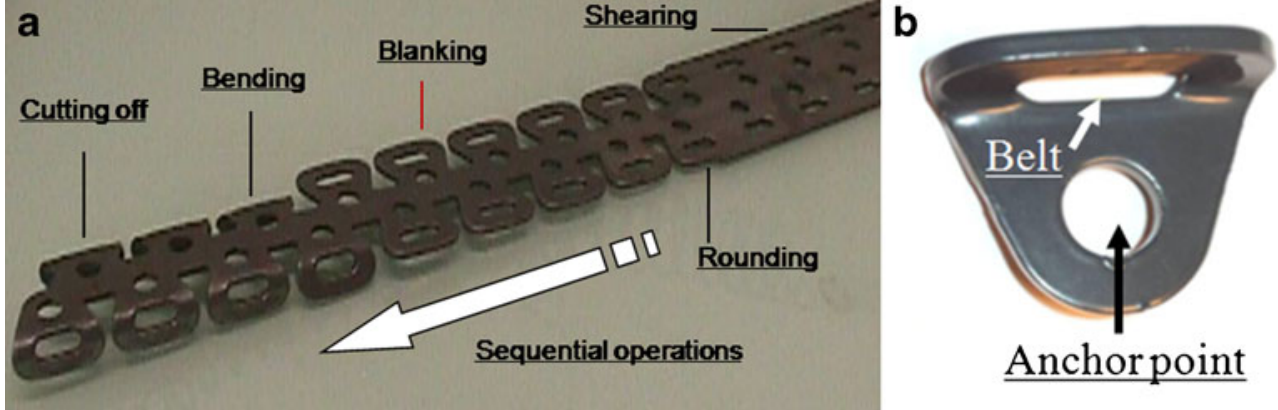

applications, Shim et al. [8] have proposed a model for blanking very thin aluminium and copper sheets. They assume that fracture of the metal takes place at a given total effective strain. In almost all studies, it is shown that accurately predicting the formation of the burr at the end of the operation is essential, given that it affects the final use of the component. Avoiding blanked components with burred edges is an industrial challenge which can be overcome by using a fine blanking operation, which is only possible on thin sheets [9]. The basics of the bending process are discussed by Marciniak and Duncan [10] in a theoretical manner, and bending applications and the Lbending process have been the focus of numerous studies (e.g. Livatyali et al. [11, 12] and Mkaddem et al. [13]). Numerical and experimental investigations have been carried out in order to predict the punching force and the elastic springback that occurs at the end of the process. In addition, obtaining a reliable product requires the optimisation of both the component and the process which is nowadays possible thanks to accurate mathematical models coupled with high-performance computers. The optimisation of the sheet metal blanking and bending processes has been studied by various authors, in order to choose the most appropriate process parameter values, such as the die radius and the clearance between the sheet and the tools $[14,15]$. In both cases, the optimisation is carried out by means of numerical simulation of the component during the manufacturing process.

The study presented hereafter is devoted to reducing the burrs caused by blanking of automotive safety belt anchors and by consequence reducing the tearing action of the burr on the seat belt material. As previously mentioned, the burr height can be directly avoided by fine blanking; however, this process cannot be successfully applied to thick components. This investigation is related to an alternative press operation for eliminating edge burrs, the E.R.P process, for which very few studies have been reported in the literature. Work can be found on the striking and fold zone in bending situations in order to minimise the elastic springback, but no information is given concerning the residual stress field or an eventual material behaviour benefit (or damage) induced by punching. Hence, there is a need to characterise the effects of the E.R.P. of blanked parts, in terms of the residual stress field of the material.

Given that finite element simulations alone are insufficient for manufacturers faced with the increasing demand for better product reliability and customer security, numerical results must be compared and validated by physical experiments. From a wider point of view, concerning sheet metal manufacturing, the choice of the optimum process depends not only on press forces but also on the sheet material behaviour. Depending on the material used for a given component, the quality of the finished product will not be the same and its behaviour under load can be radically different.

During the sequential forming operations used to manufacture the safety belt anchor shown in Fig. 1, the E.R.P. takes place between the blanking and bending operations. Hence, in order to predict the material state after bending, which conditions the in-service behaviour, the experimental characterisation of the E.R.P. is first undertaken. Specimens made of high-strength low-alloy steel (HSLA S500MC) were blanked from sheet metal in view of

Fig. 2 Different stages of the E.R.P. process

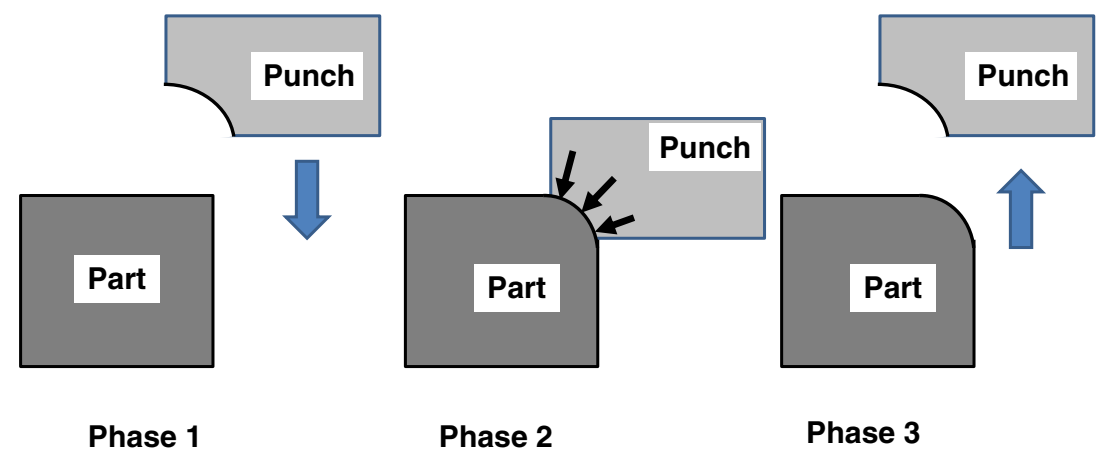


Table 1 Chemical composition of HSLA S500MC steel

\begin{tabular}{llllllllll}
\hline Element & $\mathrm{C}$ & $\mathrm{Mn}$ & $\mathrm{Si}$ & $\mathrm{P}$ & $\mathrm{S}$ & $\mathrm{Al}$ & $\mathrm{Nb}$ & $\mathrm{V}$ & $\mathrm{Ti}$ \\
\hline \%min & - & - & - & - & - & 0.01 & 0.01 & 0.01 & - \\
\%max & 0.12 & 1.7 & 0.5 & 0.03 & 0.03 & 0.1 & 0.08 & 0.08 & 0.12 \\
\%real & 0.09 & 0.19 & 0.058 & 0.014 & 0.002 & 0.044 & 0.056 & 0.043 & 0.001 \\
\hline
\end{tabular}

characterising the mechanical state of the material after the E.R.P. operation.

In the following, the experimental procedure used to study the E.R.P. is presented and the mechanical properties of the material are determined. The residual stress fields near the specimen surface are investigated by means of X-ray diffraction. The mechanical effect of the E.R.P. on specimens, which are representative of the real security part, is investigated by locally determining the Vickers micro-hardness of the material.

\section{Experimental procedure}

\subsection{Edge rounding processes}

The E.R.P. operation consists of striking the edges of the specimen with a punch having an appropriately rounded form. A schematic representation of the E.R.P. is given in Fig. 2. During the first phase, the punch descends, in the second phase the component edge is deformed plastically. In the final phase, the punch moves up and the elastic deformation is recovered.

As real components are not always well suited to laboratory experiments, two different specimens were designed in view of characterising the mechanical behaviour of the material and the effect of the E.R.P. on the component response after punching.

\subsection{Experimental work}

\subsubsection{Material and specimen shape}

The sheet metal investigated is the HSLA S500MC steel with the chemical composition given in Table 1. A blanked specimen is shown in Fig. 3. Its shape is typical of the geometry recommended by Lemaitre and Chaboche [16]. Note that the specimen dimensions are not shown in the figure; however, the specimen shape is specially chosen to concentrate the stresses at the central section of the specimen, in order to localize the mechanical phenomena. These specimens were used for tensile tests. The area of the central cross section was $48 \mathrm{~mm}^{2}(12 \mathrm{~mm} \times 4 \mathrm{~mm})$.

\subsubsection{Microscopic profile of blanked specimens}

During the blanking operation, the punching action shears the material, and a typical schematic representation of the sheared face of a specimen is shown in Fig. 4a. The burr created at the end of the mechanical operation is often kept if it is not necessary to remove it. For components coming into contact with the human body or soft materials which could be ripped, there is a need to avoid sharp edges and therefore to eliminate the burr. It is often observed that cracks initiate on the burr side of blanked specimens tested in tension (Fig. 4b). This implies a different critical state for the sheet formability in the burred zone and it indicates that further investigation of the impact of the process on the microstructure and the material properties is necessary. Figure 5 shows the fracture surfaces of different areas of the blanked profile. In these images, the shear zone (a) is characterized by a shiny appearance corresponding to the two phases of the blanking operation: work hardening and crack initiation. The rupture area (b) exhibits a ductile fracture surface while the burr zone (c) corresponds to the complete failure of the material.

\subsubsection{Edge rounding by punching}

Experimental procedure Figure 6a shows a set of modular press tools that were developed in order to round the edges of blanked test specimens. This tooling allows the punch shape to be changed to round differently shaped specimens without completely changing the tool set. Figure $6 \mathrm{~b}$ shows the punches, which have been thermally treated to improve their hardness and wear resistance.

Micrographic characteristics of edge rounded specimens An image of an edge rounded specimen, taken using an optical microscope at low magnification, is shown in Fig. 7a. The radii on both edges of the specimen are clearly visible.

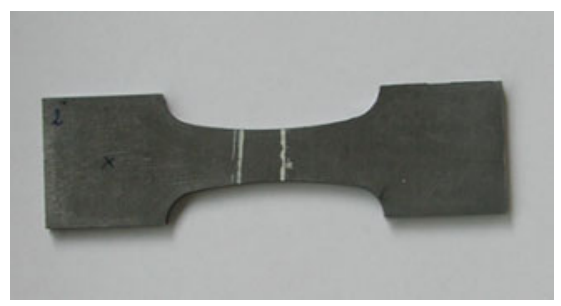

Fig. 3 Shape of the blanked specimen 
Fig. 4 Optical microscope images of the blanked profile before and after tensile testing: a the three main zones of the blanked profile; $\mathbf{b}$ blanked profile after tensile testing

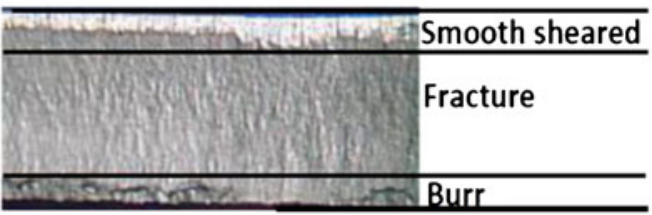

a

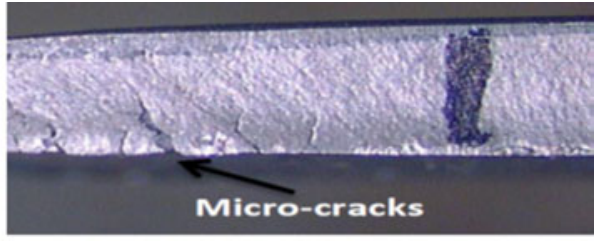

b
Figure $7 \mathrm{~b}$ shows a rounded specimen that has been subsequently tested in tension. It can be seen that the rounding operation has a positive effect on the microcracks introduced by the blanking operation. The work hardening induced by the E.R.P. modifies the microstructure of the material in the punched edges and increase its hardness. Figure 8 shows the influence of E.R.P. on the fibering of the material. It can be seen that the E.R.P. tends to fold the material in the burr zone back on itself, which achieves the desired effect of preventing tearing of other components in contact with this area.

\subsection{Experimental results and discussion}

\subsubsection{Influence of edge rounding on mechanical resistance}

Tensile tests were carried out on four sets of specimens using an INSTRON servo-hydraulic testing machine. Strain was measured using an INSTRON extensometer, with an initial gauge length of $12.5 \mathrm{~mm}$. One set of specimens consisted of blanked only specimens and the other three were composed of edge rounded specimens with punch radii of $1.25,1.75$ and $2.25 \mathrm{~mm}$, respectively. A minimum of three tensile tests were conducted for each test condition. The initial cross-sectional area of the specimens was determined by taking into account the nominal rounding radius of the punch.

Figure 9 shows the averaged stress-strain curves for the four specimen sets. It can be seen that the edge rounded specimens are more resistant than the blanked only or unrounded specimens. A significant difference can also be observed due to the different rounding radii. In particular, the yield strength and the ultimate tensile strength increase with increasing rounding radius. In terms of the percentage elongation at failure, the specimens with 1.25 and $1.75 \mathrm{~mm}$ rounding radii have the greatest ductility and the specimens with a $2.25-\mathrm{mm}$ radius have similar ductility to the unrounded specimens. This difference can be explained by the size of the work hardened zone in the rounded edges. In effect, the larger the rounding radius the greater is the rounded surface and hence the level of work hardening and the strength are increased.

Another factor influencing the strength of the specimens is the presence of micro-cracks on the blanked profile discussed in Section 2.2.2. As observed microscopically, the edge rounding operation can eliminate/repair these micro-cracks and hence influence the strength of the specimens.

Table 2 summarizes the average mechanical properties for the different sets of specimens. From these results, it can be seen that the $1.75-\mathrm{mm}$ rounding radius is the optimal radius, if both the ultimate tensile strength and the percentage elongation at failure are taken into account.

\subsubsection{Influence of edge rounding on the Vickers micro-hardness}

In order to have an indication of the strength of industrial manufactured safety belt anchors (see Fig. 1b), the material micro-hardness before and after edge rounding, with a radius of $1.75 \mathrm{~mm}$, has been investigated (see Fig. 10). Both sides of the specimen were examined in view of determining the

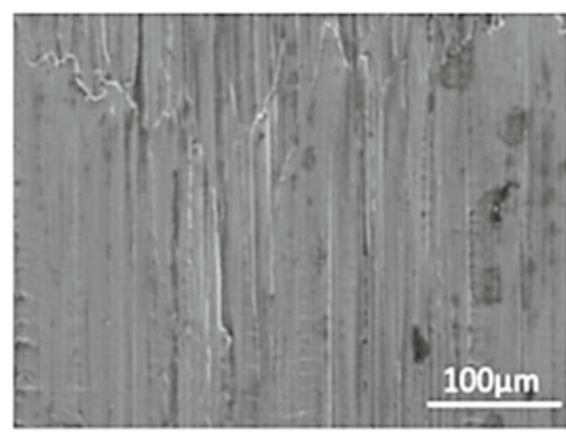

a

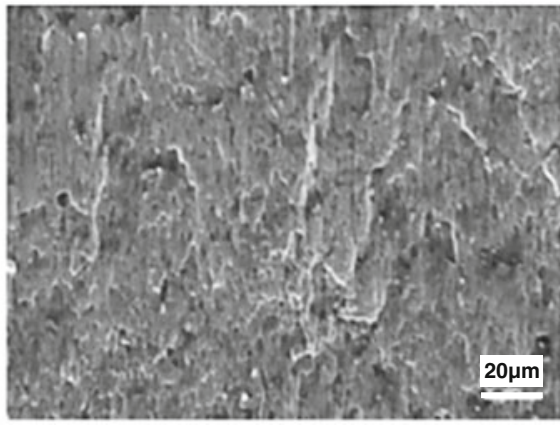

b

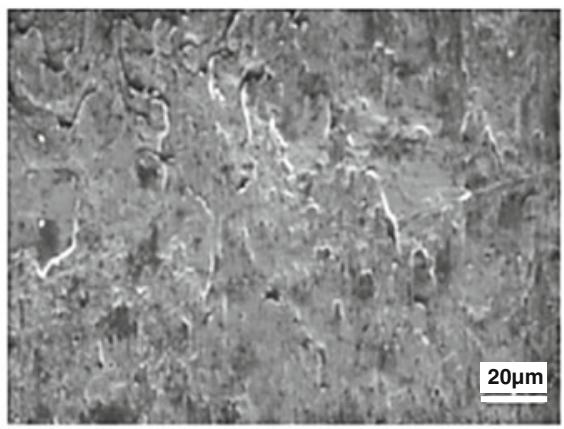

C

Fig. 5 Microscopic images of the three zones of the blanked profile: a smooth sheared zone; $\mathbf{b}$ fracture zone and $\mathbf{c}$ burr zone 
Fig. 6 E.R.P tools: a assembly view of the tooling; $\mathbf{b}$ punch geometry

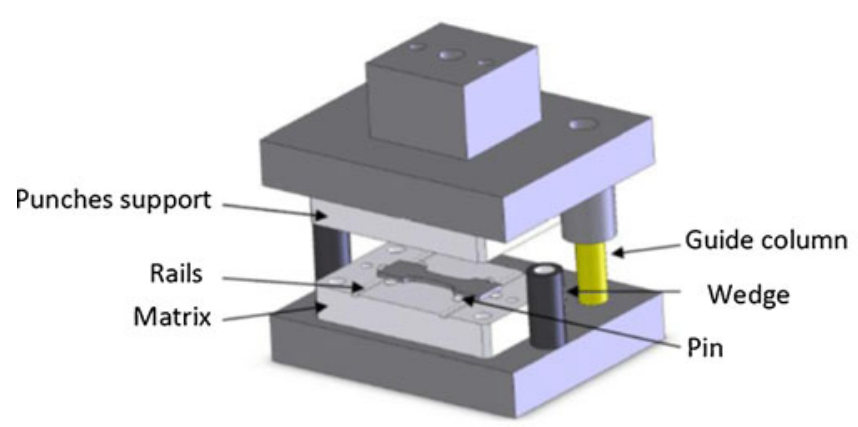

a

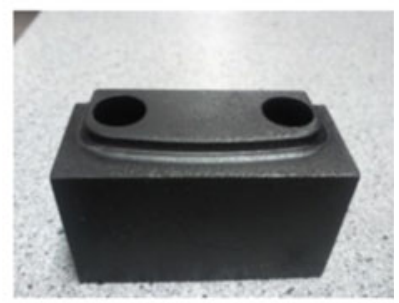

b influence of the burr on the resulting material behaviour. Blanked components were taken from the metal strip before edge rounding by punching and hardness test were carried out. The hardness test load was $20 \mathrm{~g}$.

Comparing the micro-hardness evolutions shown in Fig. 10b, c, it appears that the E.R.P operation leads to a considerable improvement in the material hardness of the order of $20 \%$.

Concerning the burr side, in addition to the advantage of eliminating the sharp edge that could cut the seat belt material, there is an increase in micro-hardness of approximately $10 \%$ near the edge. The mean micro-hardness value of three specimens decreases almost linearly with distance, but at a slower rate for edge rounded specimens as the material is more uniformly hardened. The difference between the microhardness before and after edge rounding is shown in Fig. 11 where the most significant differences between rounded and un-rounded specimens appear near the surface. It has been shown by Lemaitre et al. $[17,18]$ that the change in microhardness is able to characterise the material damage induced by loading beyond the yield strength of the material. This is particularly the case for metal forming operations $[13,19]$. If this is indeed the case, the micro-hardness evolutions indicate that the E.R.P operation leads to a considerable improvement in the material damage.

\subsubsection{Influence of edge rounding on the residual stress field}

Even though the industrial edge rounding operation is devoted to eliminating the sharp edges of the component, work hardening resulting from the operation locally increases the material strength. The stress field near the surface of the specimens in the zone of the punched edge is the superposition of a compressive stress field and the initial stress field resulting from the blanking operation. Knowledge of the residual stress field allows more accurate prediction of the in-service behaviour of the component.

The principal of stress analysis by X-rays diffraction It was therefore decided to investigate this stress field by means of the X-ray diffraction technique. The X-ray stress analysis of residual stress fields $\sigma_{i j}(z)$ that vary as a function of the depth $z$ below the surface is based on the appropriate variation of the penetration depth $\zeta$ of X-rays into the material [20]. The difference between the non-deformed and the deformed material state (Fig. 12a) gives a measure of the elastic strain in the form of:

$$
\varepsilon_{\theta}=1-\frac{\sin \theta}{\sin \theta_{0}}
$$

Fig. 7 Microscopic observations of the rounded edge: a after the E.R.P; $\mathbf{b}$ after tensile testing

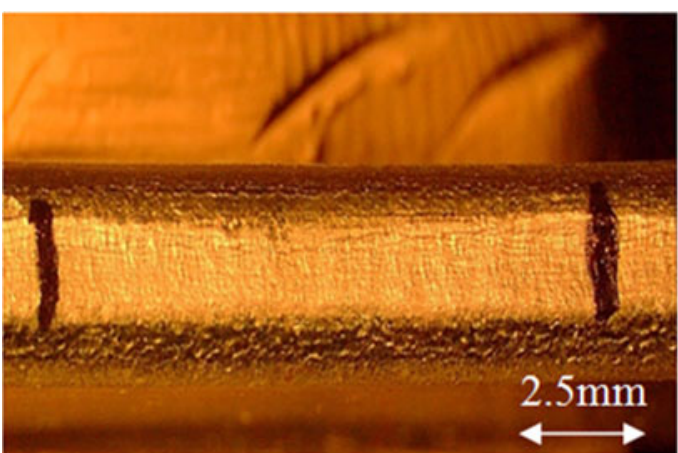

a

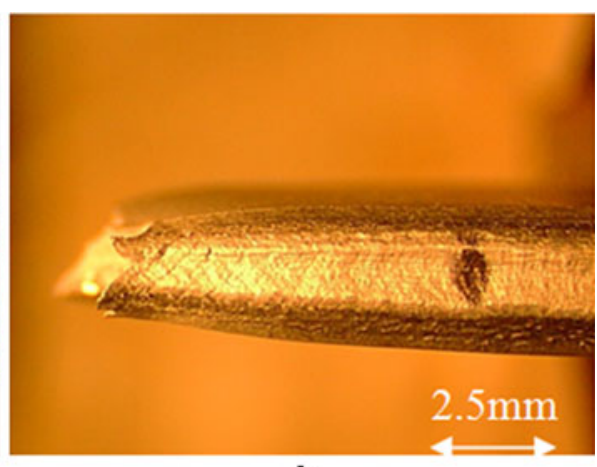

b 


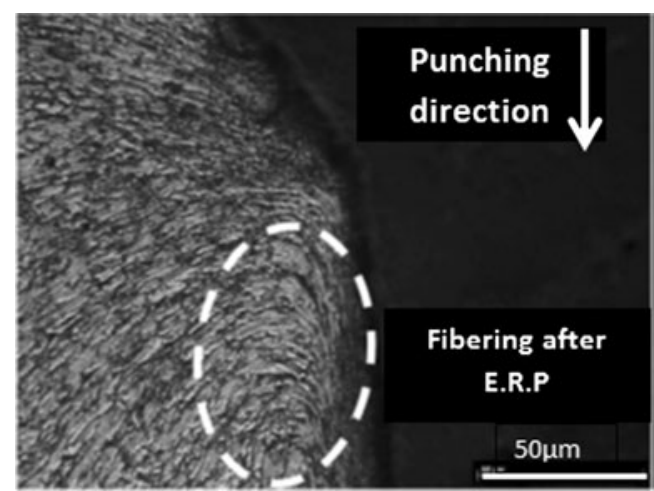

Fig. 8 Fibering direction after the E.R.P operation

The standard $\sin ^{2} \psi$ method of determining the stress involves the measurement of inter-planar spacing for various directions of the scattering vector (see Fig. 12a). For a tridimensional stress state, the strain $\varepsilon_{\theta}$ is measured in the direction of the unit vector $n_{\phi \psi}$ and the stress strain relationship is given by:

$\varepsilon_{\phi \psi}=\frac{1}{2} S_{2}\left(\sigma_{\phi}-\sigma_{33}\right) \sin ^{2} \psi+\frac{1}{2} S_{2} \sigma_{33}+S_{1} \operatorname{tr}(\sigma)+\frac{1}{2} S_{2} \tau_{\phi} \sin ^{2} \psi$

where $\sigma_{\phi}$ is the normal stress in direction ${ }_{\phi}$ and $\tau_{\phi}$ is the shear stress in direction ${ }_{\phi} . \sigma$ is the stress tensor with components $\sigma_{i j}$. The coefficients $S_{1}$ and $S_{2}$ are defined by:

$\frac{1}{2} S_{2}=\frac{1+\nu}{E} ; \quad S_{1}=-\frac{\nu}{E}$

With a sufficient number of measurements, it is then possible to determine the stresses of interest $\sigma_{\phi}$ and $\tau_{\phi}$.

Measurement conditions As shown in Fig. 13, the stresses were determined in the longitudinal and transverse directions.
Table 2 The average mechanical properties of the four different test conditions

\begin{tabular}{llll}
\hline & $\sigma_{Y}(\mathrm{MPa})$ & $\sigma_{\mathrm{UTS}}(\mathrm{MPa})$ & $A(\%)$ \\
\hline Unrounded & 605 & 700 & 21.97 \\
$R=1.25 \mathrm{~mm}$ & 619 & 726 & 26.40 \\
$R=1.75 \mathrm{~mm}$ & 657 & 769 & 26.80 \\
$R=2.25 \mathrm{~mm}$ & 707 & 799 & 21.31 \\
\hline
\end{tabular}

Once the surface stress measurements were done, electrochemical surface polishing was done in order to measure the residual stress values at different depths. Measurements were carried out using a PROTO XXRD $^{\mathbb{B}}$ machine with a $0.5-\mathrm{mm}$ collimator delivering a spot of diameter $1 \mathrm{~mm}$ on the specimen. The "XRD win" data analysis software was used.

Two series of measures were performed, the first on unrounded specimens and the second on specimens that have undergone the E.R.P. process.

In order to identify the effect of the E.R.P. and its influence throughout the specimen thickness, the stress fields were characterised at the centre and on each side of the specimens (Fig. 14), that is, the sides with and without the burr due to blanking.

Residual stresses after blanking Figure 15 presents the results of the residual stress analysis, in terms of the transverse normal stress $\sigma_{\phi}$, obtained by X-ray diffraction on the blanked edge. A tensile residual stresses state appears in the three zones increasing from the top edge to a maximum value of $450 \mathrm{MPa}$ in the burr zone. This high-tensile residual stress on the burr side is most probably the origin of the micro-cracks observed on the burr side of blanked specimens (see Fig. 4b).

Before discussing the results, it should be noted that in the experimental setup the specimens were blocked in the die and could not freely expand.
Fig. 9 Stress-strain curves for specimens with different punch radii

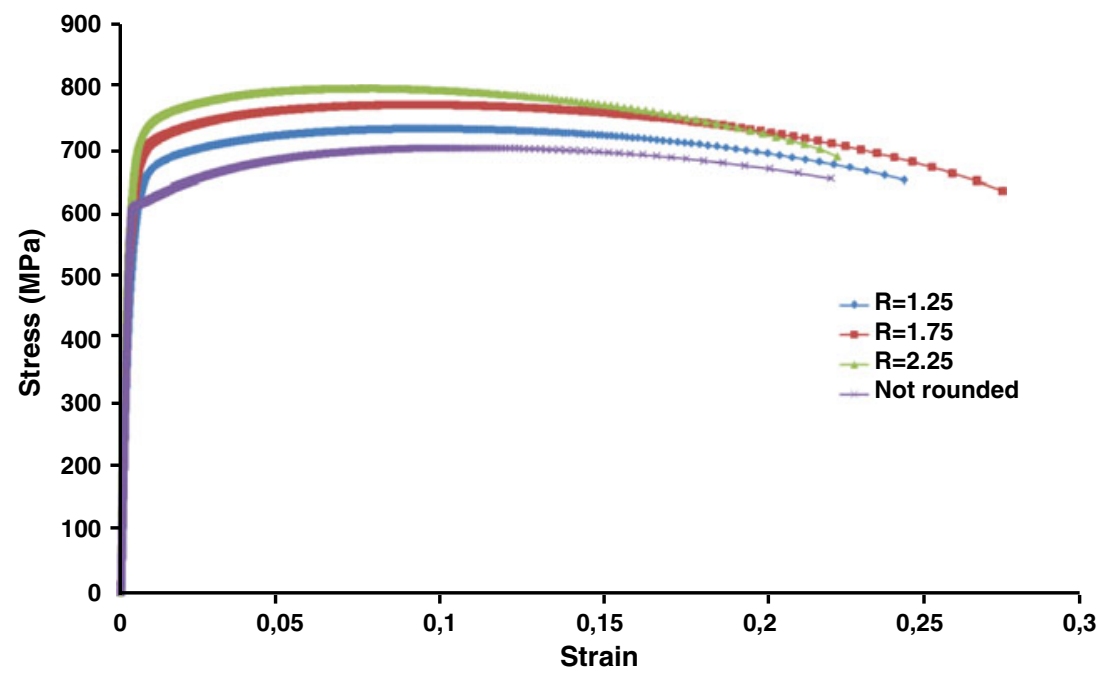


Fig. 10 Vickers micro-hardness distribution: a measurement direction; $\mathbf{b}$ un-rounded specimen; c rounded specimen $(1.75 \mathrm{~mm})$ a

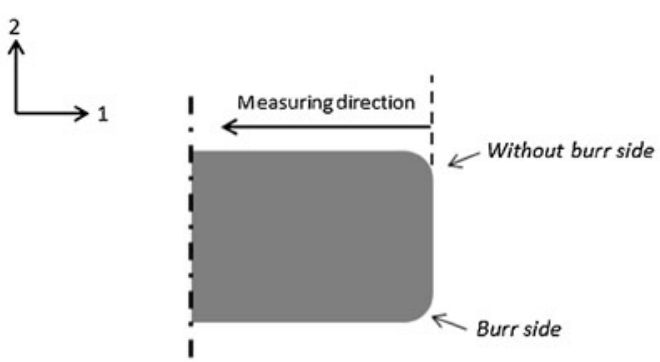

b

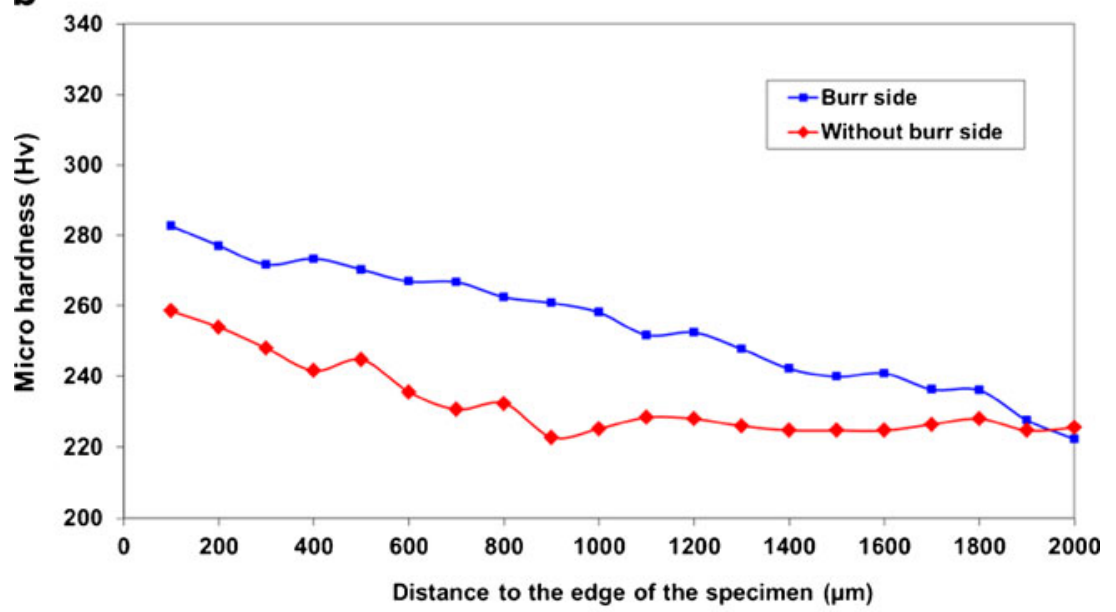

C

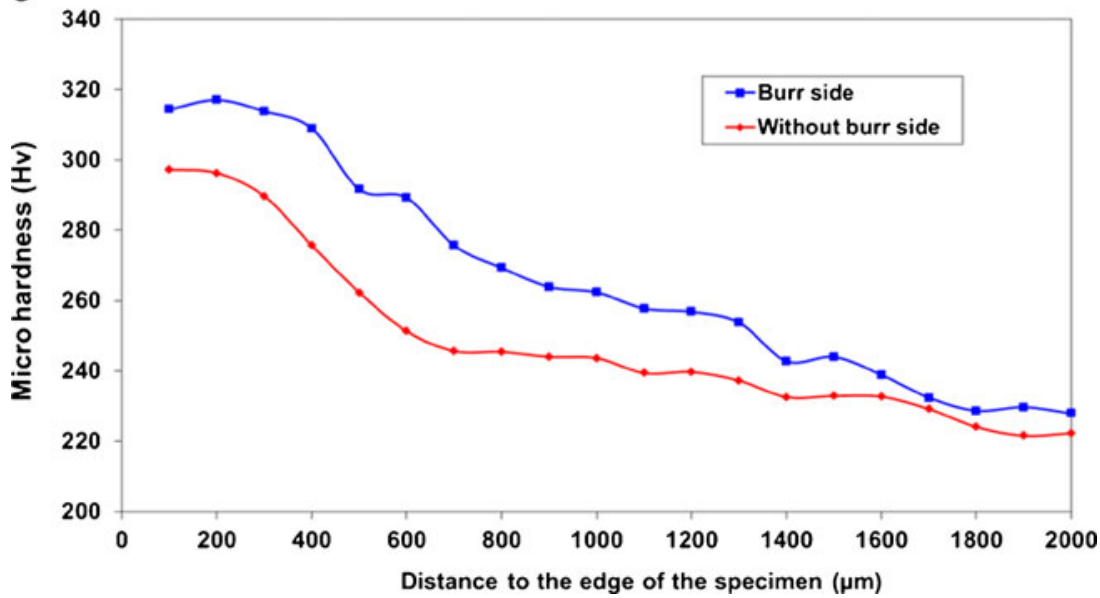

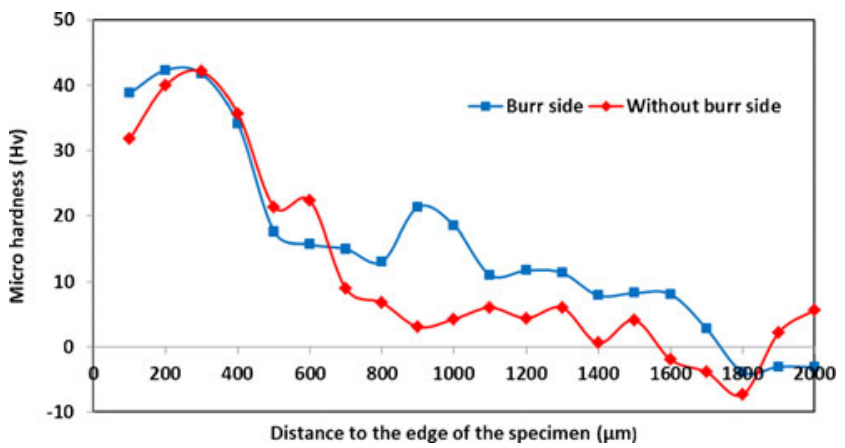

Fig. 11 Micro-hardness difference between rounded and un-rounded specimens
Residual stresses after rounding Figure 16 shows the transverse normal residual stress evolutions at the surface of the rounded edge. The $x$-axis of Fig. 16 (labelled angle) indicates the location of the measurement point on the specimen (see Fig. 14). The residual stress fields resulting from three different rounding-punch radii were analysed. For each radius, a compressive stress state is observed. Only a small difference between the three experimental values is observed, except for the first observation at angle $0^{\circ}$ for which the compressive stresses increase with increasing edge rounding radius values (from 1.25 to $2.25 \mathrm{~mm}$ ). Knowing that work hardening of the surface improves the mechanical properties of the material, it 
Fig. 12 Principal of X-rays diffraction

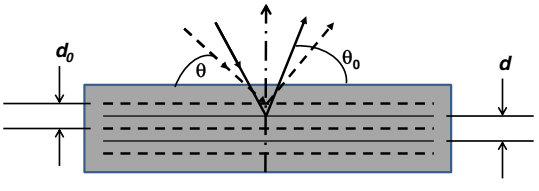

a

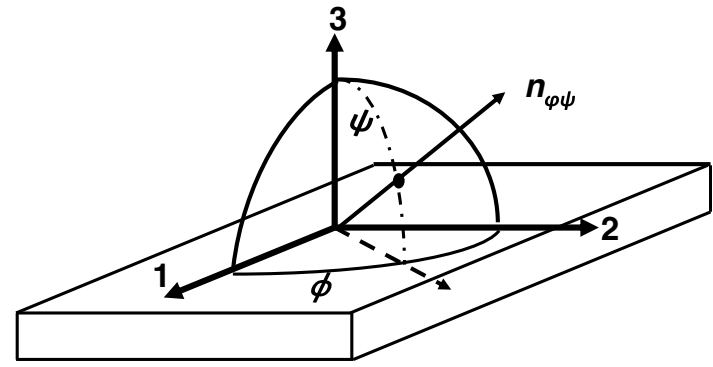

b is normal that the tensile tests reported in Section 2.3.1 exhibit better behaviour for the higher radii values. Also, the compressive stresses are higher at the burr side than at the other side, which is most probably due to the volume of material plastically deformed.

Influence of the ERP process on specimens Two set of specimens were tested: one set with rounded edges and one without.

In order to determine the effect of the E.R.P. throughout the sheet thickness, the stress fields were characterised at the centre and on each side of the specimens (i.e. the sides with and without the burr). The results are reported in Fig. 17 for specimens without rounding and in Fig. 18 for specimens with rounded edges.

Examination of Fig. 17a reveals that the stresses in the longitudinal direction are predominately positives except at the burr side, where they become negligible at a depth of about $300 \mu \mathrm{m}$. At the centre of the sheet metal, the longitudinal stress is much higher than at the two sides. The stresses in the transverse direction are shown in Fig. 17b. At the surface of both sides, the transverse stress is positive, and decreases with depth. At the centre of the thickness, the transverse residual stress is slightly negative on surface and increases rapidly within the depth to a mean value of about $350 \mathrm{MPa}$. In the transverse direction, the stress at the burr side evolves in the opposite way to the longitudinal stress. This is due to shearing of the material, while at the other sides the stresses have higher values.

Figures $18 \mathrm{a}, \mathrm{b}$ show the residual stress fields for rounded specimens, in both the longitudinal and transverse directions. The comparison between Figs. 17 and 18, for un-rounded and rounded specimens, reveals completely different material states. As expected, the E.R.P. process modifies the normal stress fields, from a predominately tensile state to a typically compressive one, and it is at the centre of the sheet metal thickness that the modifications seem to be the greatest, for both longitudinal and transverse directions.

\section{Finite Element Analyses}

\subsection{FE simulations}

The blanking and the rounding processes were simulated using two-dimensional finite element models in the ABAQUS ${ }^{\circledR}$ program. The FE models, including the boundary conditions, which are identical to the experimental conditions, are summarized in Fig. 19. The dynamic explicit finite element solver was used to simulate the blanking process. The stress and strain fields were subsequently transferred, from the ABAQUS Explicit results file to the edge rounding model. The E.R.P operation was then simulated using the static implicit method starting from the previously calculated fields, using a restart technique. The simulation was carried out using quadratic elements (CPE4R: A 4-node bilinear plane strain quadrilaterals) with reduced integration. The sheared zone between the punch and the die of the blanked material included approximately 2,400 elements, with a size of $50 \times 50 \mu \mathrm{m}^{2}$.

The plastic behaviour law was determined by tensile tests and the mechanical properties of the material are shown in Table 3. In order to model the shearing of the material during the blanking operation and to predict the shape of the blanked surface, a damage criterion for ductile metals is used. This criterion is based on a critical fracture strain value that when reached results in the removal of the element, hence
Fig. 13 Specimen position for $\mathrm{X}$-ray diffraction
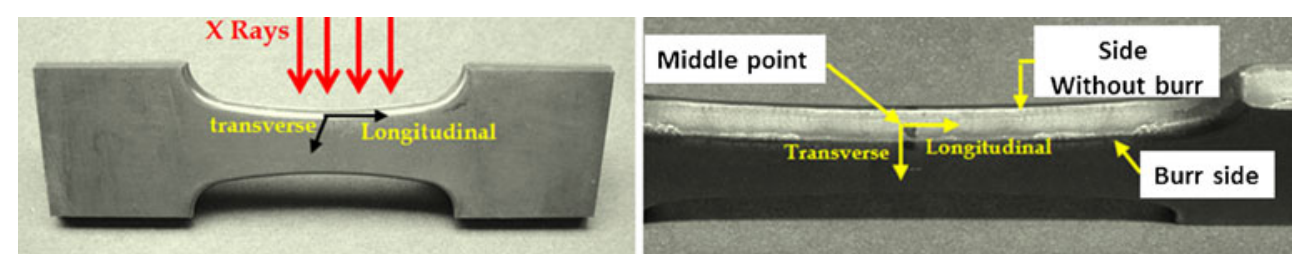


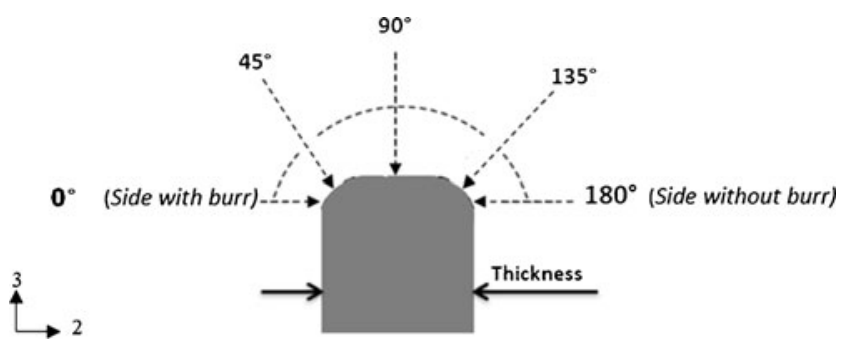

Fig. 14 Measurement points on the rounded edges

representing crack propagation. The equivalent plastic strain at the onset of damage $\left(\bar{\varepsilon}_{D}^{\mathrm{Pl}}\right)$ is assumed to be a function of the stress triaxiality $(\eta=-p / q)$ and equivalent plastic strain rate $\left(\dot{\varepsilon}^{p l}\right)$. Where $p$ is the hydrostatic stress and $q$ is the von Mises equivalent stress. This function is based on empirical correlation and is a standard feature of the ABAQUS program [21].

The criterion for damage initiation is met when the following condition is satisfied:

$W_{D}=\int_{0}^{\varepsilon_{D}} \frac{d \bar{\varepsilon}^{p l}}{\bar{\varepsilon}_{D}^{p l}(\eta)}=1$

Where $W_{D}$ is a state variable that increases monotonically with plastic strain. At each increment during the analysis, the incremental increase in $W_{D}$ is computed as:

$\Delta W_{D}=\frac{\Delta d \bar{\varepsilon}^{p l}}{\bar{\varepsilon}_{D}^{p l}(\eta)} \geq 0$

Critical fracture values have been experimentally determined for two different states of stress triaxiality by means of tensile tests and shear tests (see Table 3). The shape and dimensions of the shear specimen were defined in [22]. The critical fracture values used in this work provide good agreement between the experimental results and FE simulations of tensile and shear tests. A coefficient of fiction of $\mu=0.2$ was used in the simulation of the blanking and the rounding processes.

\subsection{Results and discussions}

In the following, the von Mises equivalent stress is used to define and compare the residual stress state, which is by definition is a complex three-dimensional stress state with interaction between the components of the stress tensor. This is common approach used by other authors [23].

\subsubsection{Analysis of the blanked profile}

Figure 20 shows the comparison between the numerically simulated blanked profile and the experimentally observed profile. The left half of the figure shows the predicted profile (seen from the side) and the right half of the figure is a front view of a blanked surface. The simulation of the blanking operation uses the rupture criterion described by Eq. (4). After elastic springback, the E.R.P. operation is simulated using an elasto-plastic material constitutive law. Three zones on the sheared face can be identified from the finite element model, which correspond to the three experimentally observed zones, discussed in Section 2.2.2 above. However, as shown in Fig. 20, there is a difference in the size of the numerical and experimental zones. This difference is most probably due to inaccuracies in the damage model which is not coupled with the material behaviour law.

\subsubsection{Comparison between the numerical and the experimental blanked specimens}

Figure 21 shows the comparison between the residual stresses determined experimentally and numerically, within the depth of the material, in the shear zone of blanked specimens. The stresses are presented in the form of the von Mises equivalent stress. Both the numerical and experimental results show that the stress is highest on the surface and decreases within the depth of the material and appear to stabilize at a depth of approximately $150 \mu \mathrm{m}$. This can be explained by the dominance of the normal stresses in the longitudinal and transverse directions close to the surface of the specimen, created by the blanking operation. Figure 22a shows that the maximum calculated value of the maximum in-plane principal stress is $718 \mathrm{MPa}$ at the surface in the middle of the specimen thickness.
Fig. 15 Transverse normal residual stresses $\sigma_{\phi}$ at the surface of the blanked profile

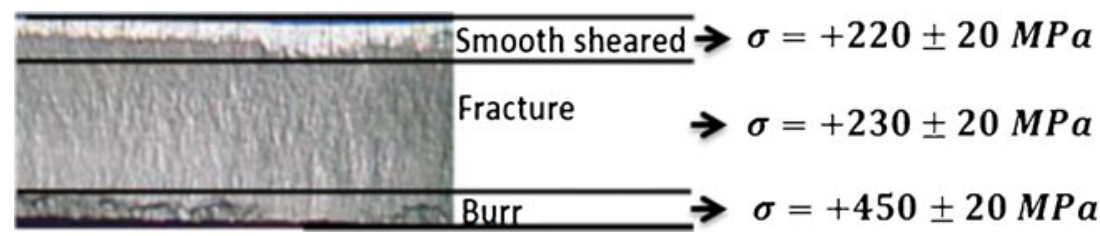


Fig. 16 Variation of transverse normal residual stresses $\sigma_{\phi}$ at the surface of rounded edge as a function of the angle (defined in Fig. 14)

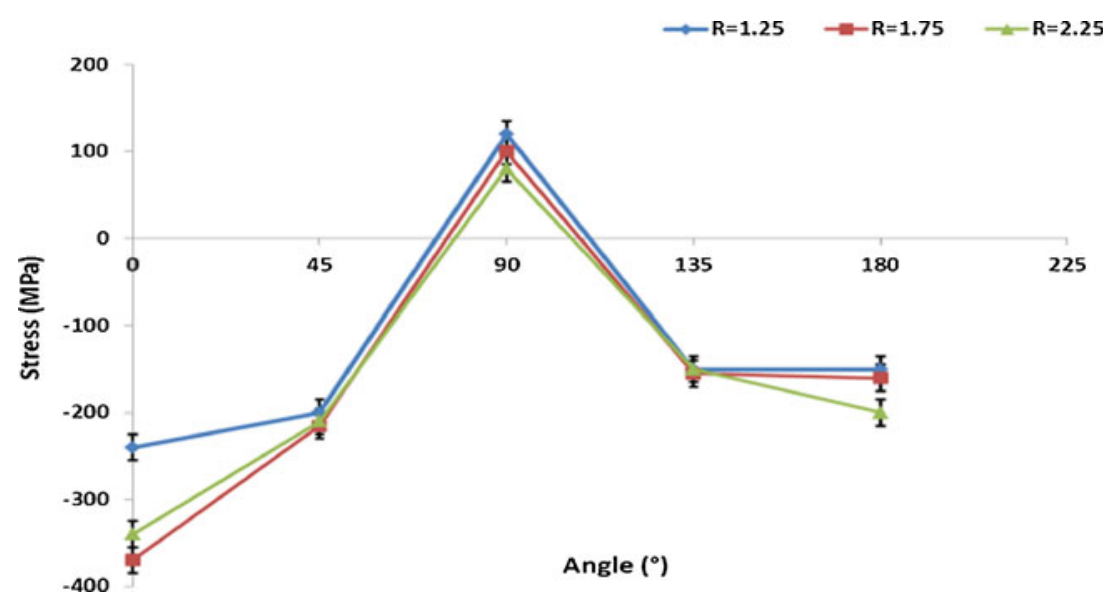

3.2.3 The influence of the rounding operation on the residual stress distribution rounding process, the E.R.P was simulated for the following two cases:

- Simulation of the blanking operation followed by simulation of the rounding by punching operation, including the

With the aim of quantifying the influence of the inter-

Fig. 17 Evolution of the residual stress $\sigma_{\phi}$ in unrounded specimens $(R=1.75 \mathrm{~mm}):$ a longitudinal direction; $\mathbf{b}$ transverse direction
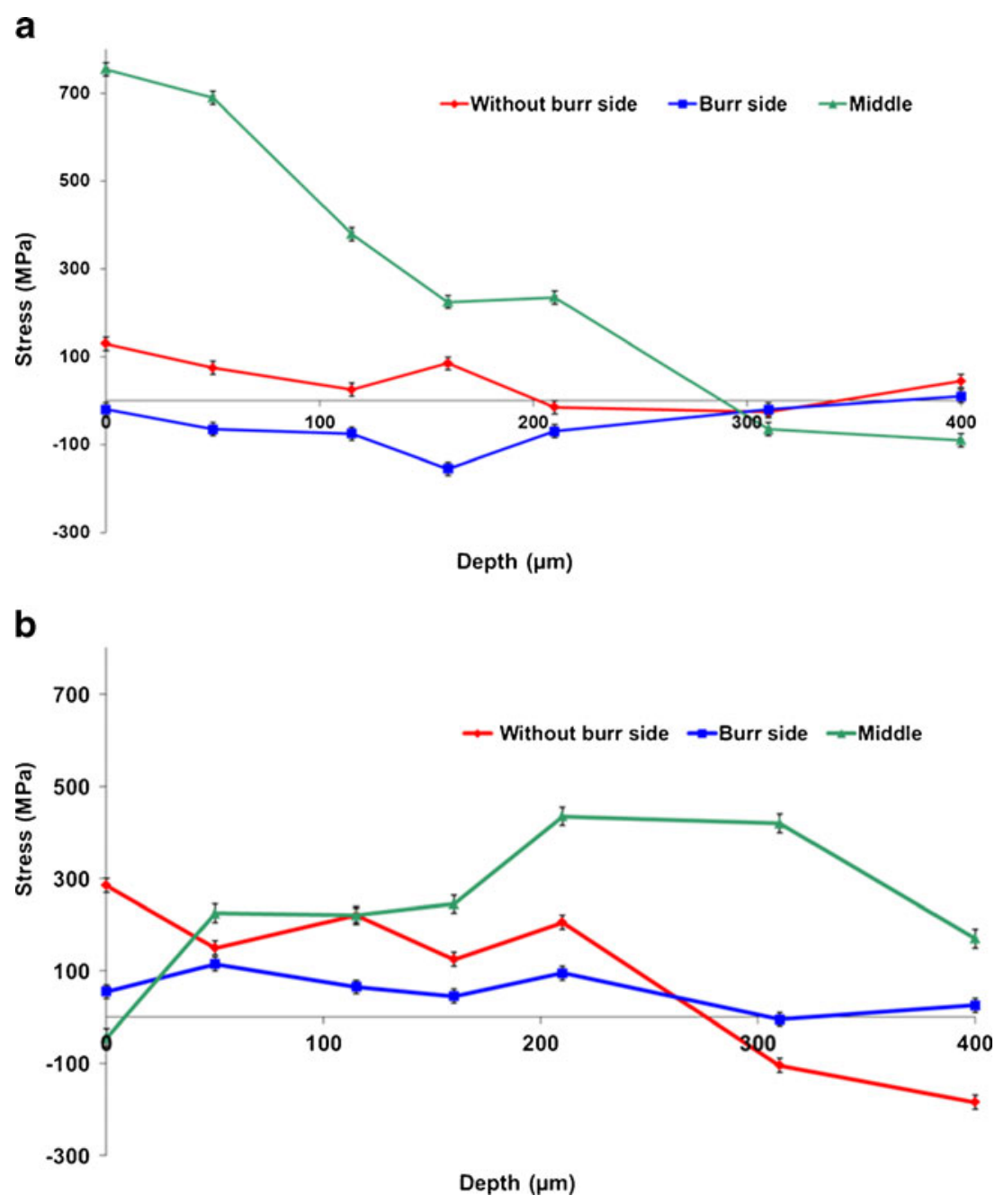
Fig. 18 Residual stress $\sigma_{\phi}$ distributions as a function of depth, for edge rounded specimens $(R=1.75 \mathrm{~mm})$ : $\mathbf{a}$ in the longitudinal direction; $\mathbf{b}$ in the transverse direction
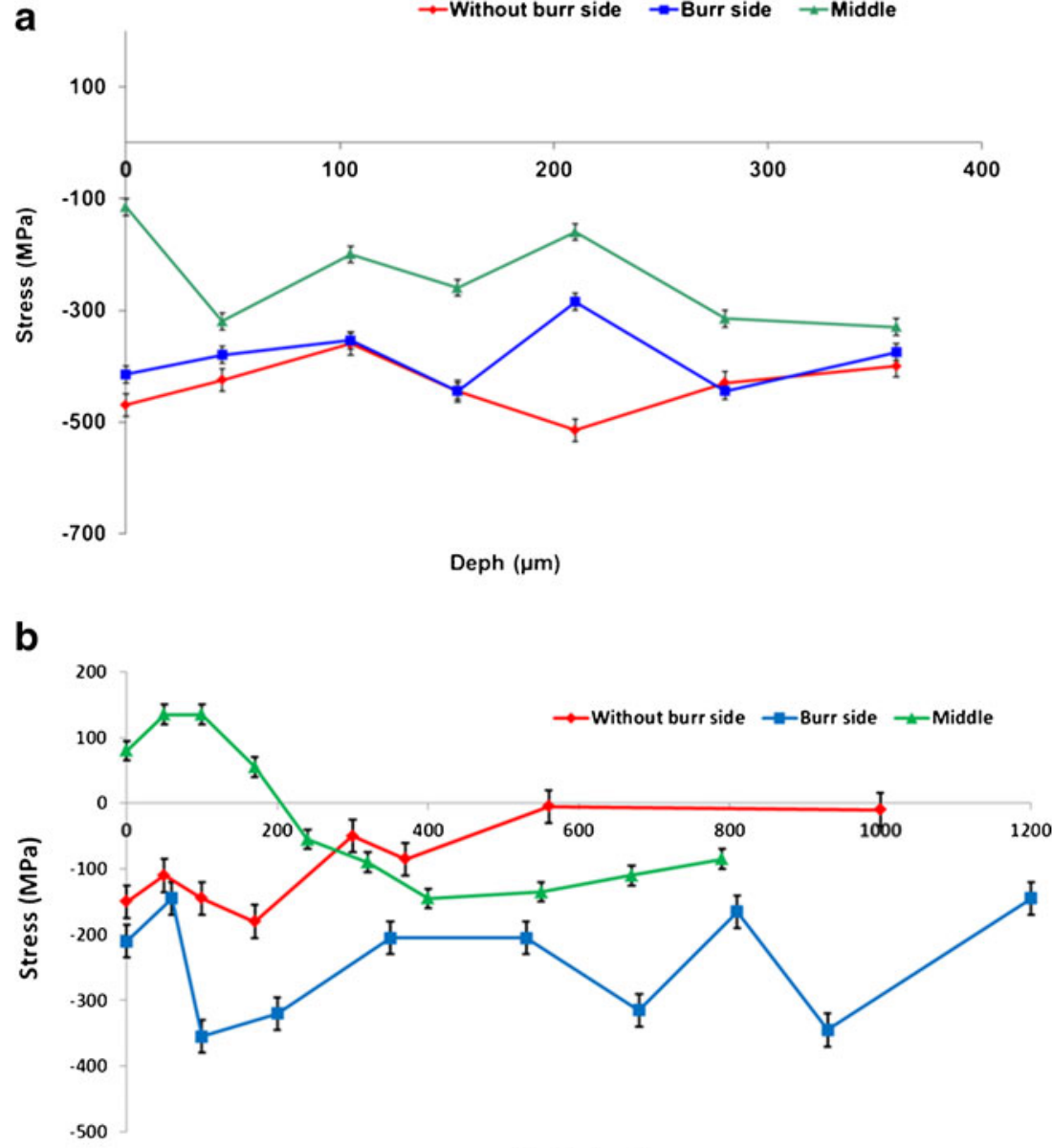

Depth $(\mu \mathrm{m})$ transfer of the residual stress and strain fields between the two simulations,

- Simulation of the rounding by punching operation on a virgin specimen (without initial stress and strain fields after blanking).

Figure 22b, c shows the residual stress fields corresponding to these two cases.

Fig. 19 FEM simulations: a section of the specimen modeled; b the blanking process model and c the E.R.P. model (model parameters: $P=5.6 \mathrm{~mm}, B=$ $10 \mathrm{~mm}, R_{\mathrm{p}}=R_{\mathrm{d}}=0.1 \mathrm{~mm}, R_{\mathrm{B}}=$ $0.2 \mathrm{~mm}, \mathrm{Cl}=0.4 \mathrm{~mm}, L=4.4 \mathrm{~mm}$, $\left.R_{\mathrm{p}}^{\prime}=1.75 \mathrm{~mm}, r_{\mathrm{p}}=0.25 \mathrm{~mm}\right)$

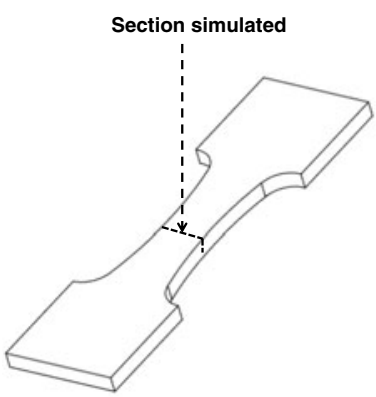

a

The rounded profile, after simulation of the blanking operation, is characterized by a compressive residual stress state with a maximum compressive stress of $-656 \mathrm{MPa}$ in the shear zone. This level of stress is similar to the values observed experimentally (see Fig. 18). This observation explains the importance of the rounding operation to improve the mechanical behaviour of the component by the creation of compressive residual stresses at the edges.

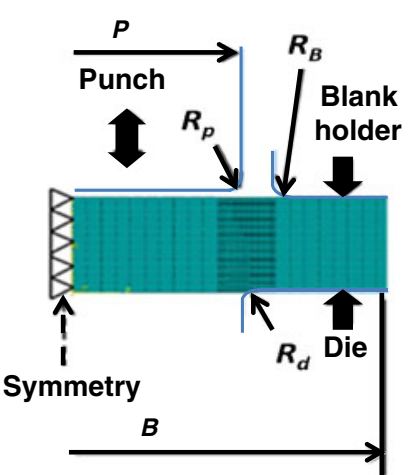

b

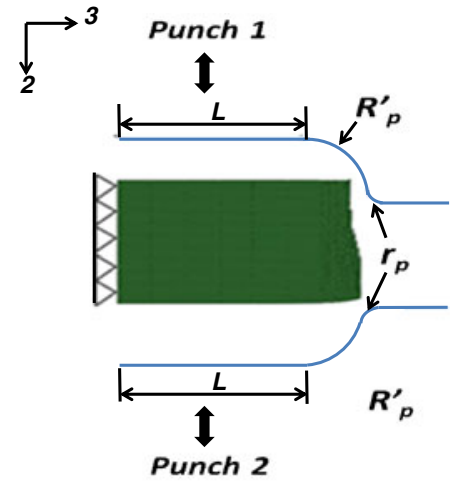

C 
Table 3 Simulation conditions

\begin{tabular}{ll}
\hline Simulation model & 2D model (plane strain) \\
\hline Parts & Workpiece: deformable (elastic-plastic) \\
& Punches (blanking and ERP): analytic rigid \\
& Blank holder: analytic rigid \\
& $E=210 \mathrm{Gpa}, v-0.28$ \\
Elastic properties & $\sigma=564+585 \varepsilon_{\mathrm{pl}}^{0.5}$ \\
Plastic behaviour law & Von Mises \\
Yield criterion & In tenion $\left(\bar{\varepsilon}_{\mathrm{R}}^{\mathrm{Pl}}=0.21\right)$, in shear $\left(\varepsilon_{\mathrm{R}}^{\mathrm{Pl}}=0.83\right)$ \\
Critical fracture strain &
\end{tabular}

\begin{tabular}{|c|c|l|l|}
\hline & Burr \\
& $\begin{array}{l}\text { Fracture } \\
\text { surface }\end{array}$ \\
& Shear surface \\
\hline
\end{tabular}

Fig. 20 Comparison between the numerically predicted blanked profile (viewed from the side) and the experimental observed profile (viewed from the front)

In Fig. 22b, a peak stress of approximately $-540 \mathrm{MPa}$ can be seen just below the surface in a zone of relatively homogeneous moderate compressive stress.

The middle zone of Fig. 22b shows a heterogeneous stress field which is predominately tensile with an average value of approximately $75 \mathrm{MPa}$. This value is largely inferior to the stress level obtained after the blanking operation (Fig. 22a). Also, the level of the surface residual stress highlights the importance of the rounding operation for the elimination of the tensile residual stress introduced by blanking.
Figure 23 shows the comparison of the residual stress values as a function of depth, for a blanked and then rounded specimen. In the rounded zones, good correlation between the numerical and experimental results is observed. However, a significance difference can be seen in the middle zone. This difference can probably be explained by the inaccuracies in the fracture model used in this zone which corresponds to the tearing of the material. The middle zone is subjected to a loading condition which results in stress triaxiality that is close to zero. However, the uncoupled damage model does not take into account this phenomenon and results in a predicted stress state that is different to the experimental one. For this reason, a coupled damage-plasticity model that integrates the effect of low stress triaxiality is a relevant research topic that is currently being investigated.

\section{Conclusion}

During the sequential manufacturing of automotive security components, blanked edges are rounded by punching in a separate operation. In order to characterise the influence of edge punching, different experimental investigations were carried out on the both sides of blanked specimens. Both sides were subjected to residual stress analysis by means of X-ray diffraction and Vickers micro-hardness tests. X-ray diffraction investigations have shown that the E.R.P. superimposes a compressive stress field with the existing one. It was found that the initial tensile stress field is replaced by a compressive stress field which is known to improve the material behaviour by strain hardening. Confirmation was obtained by carrying out micro-hardness tests on both sides of blanked specimens. Moreover, micro-hardness experiments can be analysed in order to characterise the material damage which may appear during the edge punching operation. Experimentally, microhardness tests and the X-ray diffraction analyses to determine
Fig. 21 Comparison between the residual stresses determined experimentally and numerically, within the depth of the material, of blanked specimens

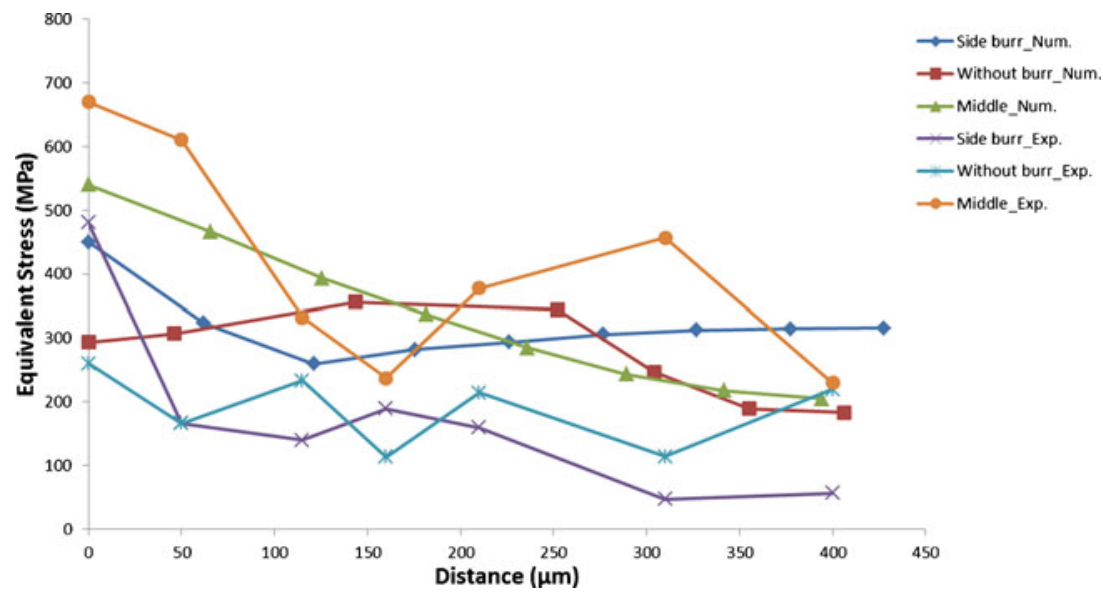


Fig. 22 The equivalent stress and the maximum in-plane principal stress, for simulation of a the blanking operation; b rounding after blanking; c rounding of a virgin specimen

\section{a}

S, Mises

(Avg: 75\%)
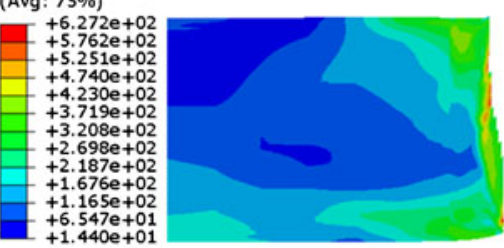

S, Max. In-Plane Principal

(Avg: 75\%)

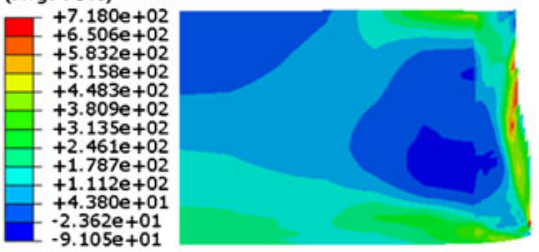

b S, Mises
(Avg: $75 \%$ ) (Avg: $75 \%$ ) $\begin{aligned} & +1.068 \mathrm{e}+03 \\ & +9.797 \mathrm{e}+02 \\ & +8.914 \mathrm{e}+02\end{aligned}$ $+8.914 \mathrm{e}+02$ $+7.148 \mathrm{e}+02$ $+6.265 \mathrm{e}+02$ $+5.382 \mathrm{e}+02$ $+4.499 \mathrm{e}+02$ $+2.733 \mathrm{e}+02$ $+1.850 \mathrm{e}+02$ $+9.670 \mathrm{e}+01$
$+8.400 \mathrm{e}+00$

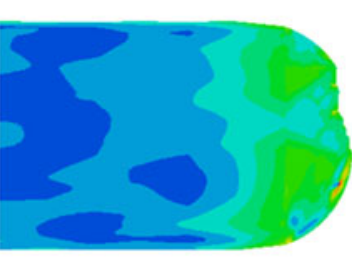

S, Max. In-Plane Principal (Avg: $75 \%$ )

C S, Mises
(Avg: $75 \%$ ) Avg: $75 \%$ ) $+6.223 \mathrm{e}+02$

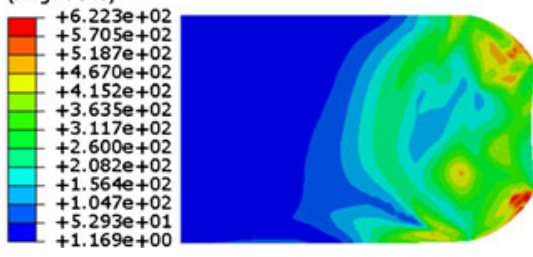

S, Max. In-Plane Principal (Avg: 75\%)

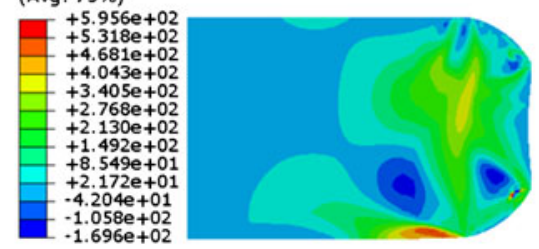

the residual stresses confirm that the E.R.P. induces material strain-hardening down to the mid-thickness of the specimens. On both sides of a blanked specimen, it is shown that the E.R.P. significantly increases the material hardness, in addition to smoothing the burr side.

In view of optimising the process, which implies varying certain parameters such as the punch radius and its penetration, numerical simulations have been carried out and implemented in an FE code. The material damage was accounted for by means of a critical strain criterion. The results of the numerical simulations show good agreement with the experimental results. It can be concluded that the numerical simulation of the E.R.P. is a reliable tool allowing for the prediction of the residual stresses field which may influence the mechanical behaviour of the component.

A micro-mechanical coupled plasticity-damage model that takes into account the effect of low stress triaxiality during the blanking operation has been put in place and is in the process
Fig. 23 Equivalent residual stress as a function of depth, after blanking and ERP

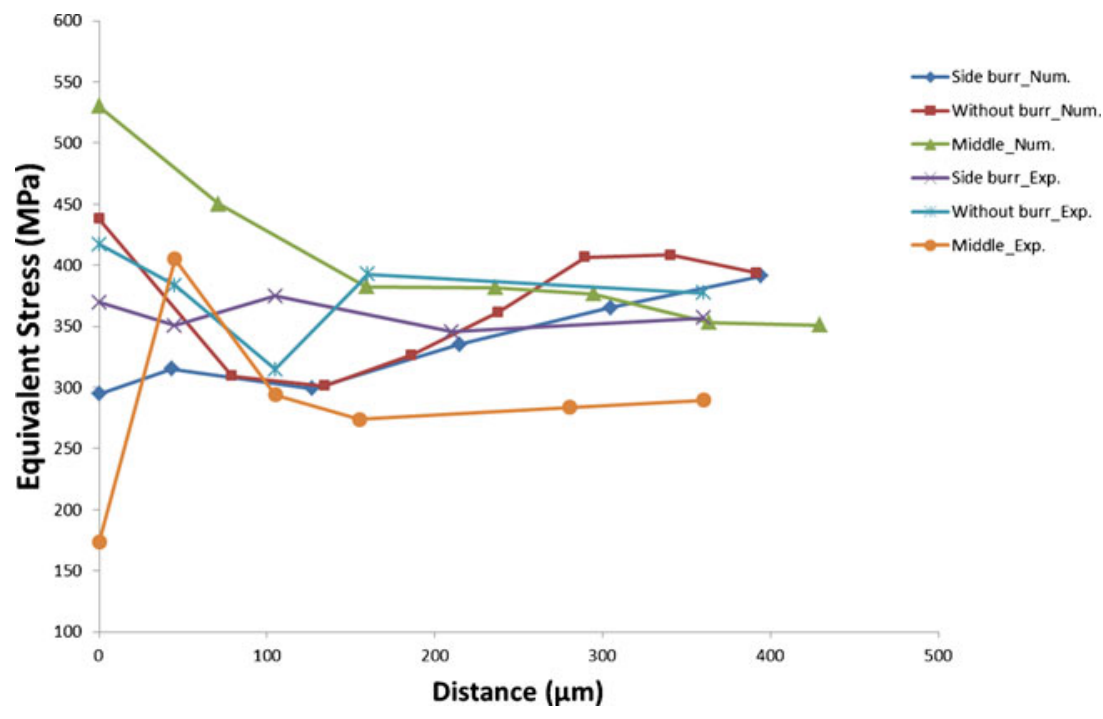


of being validated for the blanking operation and the interaction with the other operations such as rounding and bending. These results will be presented in a future communication.

Acknowledgments The authors wish to thank Deville S.A. Company for its support.

\section{References}

1. Sacks J, Welch WJ, Mitchell TJ, Wynn HP (1989) Design and analysis of computer experiments. Stat Sci 4:409-435

2. Welch WJ, Yu TK, Kang SM, Sacks J (1990) Computer experiments for quality control by parameter design. J Qual Technol 22:15-22

3. Gosh A, Popat PB, Raghu V (1985) A new approach to the mechanics of the blanking operation. Theoretical model and experimental verification. J Mech Work Technol 11:215-228

4. Maillard A (1991) Experimental and theoretical study of blanking. $\mathrm{PhD}$ Thesis. University of Technology of Compiègne

5. Klingerberg W, Singh UP (2003) Finite element formulation of the punching blanking process using in-process characterisation of mild steel. J Mater Process Technol 134:296-302

6. Thipprakmas S, Jin M, Murakawa M (2007) Study on flanged shapes in fineblanked-hole flanging process (FB-hole flanging process) using finite element method (FEM). J Mater Process Technol 192193:128-133

7. Hambli R, Potiron A (2000) Finite element modelling of sheet-metal blanking operation with experimental verification. J Mater Process Technol 102:257-265

8. Shim KH, Lee SK, Kang BS, Hwang SM (2004) Investigation on blanking of thin sheet metal using the ductile fracture criterion and its experimental verification. J Mater Process Technol 155-156:19351942

9. Kim SS, Han CS, Lee YS (2005) Development of a new burr-free hydro-mechanical punching. J Mater Process Technol 162-163:524529

10. Marciniak Z, Duncan J (1992) Mechanics of sheet-metal forming. First published E. Arnold, London
11. Livatyali H, Altan T (2001) Prediction and elimination of springback in straight flanging using computer aided design methods. Part 1 experimental investigations. J Mater Process Technol 117:262-268

12. Livatyali $\mathrm{H}, \mathrm{Wu} \mathrm{HC}$, Altan $\mathrm{T}$ (2002) Prediction and elimination of springback in straight flanging using computer aided design methods. Part 2 FEM predictions and tool design. J Mater Process Technol 120: $348-354$

13. Mkaddem A, Potiron A, Lebrun JL (2002) Straightening and bending process characterization using Vickers micro hardness technique, Proceeding of International Conference of Advanced Technology of Plasticity, Tokyo, Japan, Oct. 27-Nov.1, 2002, Proceedings Institute of Industrial science, The University of, Komaba, 631-636

14. Hambli R (1996) Theoretical, numerical and experimental study of sheet-metal blanking operation in view of the process optimization. $\mathrm{PhD}$ Thesis. ENSAM Angers

15. Hambli R, Guérin P (2003) Application of neural networks for optimum clearance prediction in sheet-metal blanking process. Finite Elem Anal Des 39:1039-1052

16. Lemaitre J, Chaboche JL (2004) Mécanique des Matériaux Solides. Dunod

17. Mkaddem A, Gassara F, Hambli R (2006) A new procedure using the microhardness technique for sheet material damage characterisation. J Mater Process Technol 178:111-118

18. Lemaître J, Dufailly J, Billardon R (1987) Evolution of damage by microhardness measuring. Comptes Rendus de l'Académie des Sciences, 601-604

19. Mkaddem A, Bahloul R, Dal-Santo P, Potiron A (2006) Experimental characterisation in sheet forming processes by using Vickers micro hardness technique. J Mater Process Technol 180:1-8

20. Hauk V (1997) Structural and residual stress analysis by nondestructive methods. Elsevier, Amsterdam

21. Abaqus (2009) Analysis user's manual (Version 6.9)

22. Achouri M, Germain G, Dal Santo P, Saidane D (2013) Experimental characterization and numerical modeling of micromechanical damage under different stress states. Mater Des 50:207-222

23. Martins JA, Cardoso LP, Fraymann JA, Button ST (2006) Analyses of residual stresses on stamped valves by X-ray diffraction and finite elements method. J Mater Process Technol 179:30-35 